\title{
Mixed structured physical exercise program for obese workers: combating sedentary and metabolic risk factors related to metabolism workplace syndrome
}

\author{
(D) Godefroid Kusuayi Mabele ${ }^{1}$, (D) Constant Nkiama Ekisawa ${ }^{1}$ \\ (iD) Betty Miangindula ${ }^{1}$, (D) Christophe Delecluse ${ }^{2}$, \\ (D) François Lepira Bompeka ${ }^{3}$ (D) Pierre Akilimali ${ }^{4}$

\begin{abstract}
${ }^{1}$ Kinesiology Service, Department of Physical Medicine and Rehabilitation, University of Kinshasa Faculty of Medicine, Democratic Republic of Congo.

2 Faculty of Movement and Rehabilitation Sciences Department of Movement Science K. Leuven, Belgium.

${ }^{3}$ Nephrology service, Department of Internal Medicine, University of Kinshasa Faculty of Medicine, Democratic Republic of Congo.

${ }^{4}$ School of Public Health, Department of Epidemiology, Faculty of Medicine, University of Kinshasa.
\end{abstract}

\begin{abstract}
To develop a program of high volume physical exercises, of moderate to high intensity, adapted to the working context of Kinshasa. In a trial study of structured, spontaneous and mixed physical exercise programs associated with nutrition education, lasting 3 months, from November 7 to January 7, 2014. 30 obese sedentary workers $44 \pm 844 \pm 8.6$ on average, year-olds were randomly selected from 157 obese individuals out of a general population of 400 employees in the personal list of the selected company. These workers were divided into three groups of physical exercises, of which the first group consisted of 10 workers in a three-day, moderate to high intensity structured exercise program, including: jogging, aerobics, basketball, volleyball, swimming, abdominals and walking of 10,000 steps a day. The second group was also composed of 10 workers undergoing a spontaneous exercise program of the same duration, intensity and frequency including: walk, up and down the stairs and finally the third group composed and then the third group of 10 workers submitted to a mixed exercise program (the mixture of the two programs). Quantitative variables were expressed as mean \pm standard deviation. The ANOVA test was used to compare the variables of two groups. A value of $p$-value $\leq 0.05$ was considered a threshold of statistical significance. Decreased weight, waist
\end{abstract}

circumference and body mass index were observed intra group before and after exercise programs. After the intervention, the group subjected to the mixed exercises improved more significantly $(\mathrm{p}=0.0001)$ the morphological parameters of the obese than the group subjected to the structured and spontaneous exercises with diet. A moderate to high intensity, high volume mixed exercise program significantly improves the morphology of obese sedentary workers compared to the structured and spontaneous exercise program. It can be considered as an effective non-pharmacological strategy to combat the nutritional and epidemiological transition in the workplace, where obesity is the main cornerstone.

Keywords. Mixed exercises, nutrition education, spontaneous exercise, structured exercises.

\section{Introduction}

Sedentary lifestyle, the main health factors related to lifestyle. It must be widely understood if one wants to reduce the benefits of sufficient physical activity (Hippocrates, 2002). However, as researchers increasingly understand the impact of physical activity on health, few decision makers 
seem to be aware of the need for global action (Chakravarthy et al., 2002; Han et al., 1997).

Several evaluations of available scientific data have shown that physical activity can be beneficial to the morphological health of sedentary obese (Verori et al., 2004; Pedersen et al., 2006; Van et al., 1991; Bucher et al., 2000). Obesity has become the first non-infectious disease in the history of mankind. It is a real epidemic affecting both industrialized and resource poor countries.

Although multifactorial, the causes most often mentioned to explain the emergence of obesity are a genetic predisposition associated with a sedentary lifestyle and / or unhealthy diet occupy a prominent place (Ross et al., 2001; Heyward et al., 2010).

The overall management of obesity involves both physiological and psychological mechanisms for initial weight loss through different exercise programs with or without a diet adapted to the environment and health problems.

The professional environment is synonymous with the requirements of productivity, efficiency, results, growth, does not promote the practice of sufficient physical activity and discourages healthy eating behavior. But the human body is a wonderful machine whose optimal functioning is through movement. (Scherr et al., 2013; Fung et al., 2001; Van et al., 1991; Roberts et al., 2009; Grundy et al., 2005).

Medium- and long-term consequences lead to health problems, work accidents and absenteeism as physically active employees are more profitable and healthy employees. (Ross et al., 2001; Heyward et al., 2010; Alberti et al., 2005; Dietz et al., 1996). Business leaders, human resources directors, and health and safety managers know that it is good to have healthy employees. Scientific research has shown that regular physical activity reduces the risk of many diseases and offers many benefits for the employee and the employer. In addition, a context-specific exercise program appears to be a preferred means of improving the morphological health of the obese worker (Poon et al., 2000; Fung et al., 2001).
In Kinshasa, no study has considered the development of this program adapted to obese sedentary workers. In the workplace, employees cannot escape the epidemiological transition whose sedentary lifestyles and obesity are the main contributors.

It is a fact that business leaders, the occupational health departments and the medical services of Kinshasa are much more concerned with health care expenditures than with the prevention of sedentary lifestyle and obesity as well as the cardio-metabolic risks associated specifically in the context of occupational health.

Hence the awareness of the seriousness of the situation, the present study develops structured, spontaneous and mixed exercise programs with low-calorie diet, rich in fiber and vitamins to show which of this program would improve the morphology by report to others among workers in the city of Kinshasa suffering from obesity.

\section{Methods}

This experimental study occurred in the period from November 7 to January 7, 2014. The Multimodal Freight Management Office of Kinshasa, in the Democratic Republic of Congo, served as a framework for this study.

The population of this study included 157 obese workers selected from a general population of 400 workers seen during the period of our study and listed on the personal list of the company. In this population of 157 obese workers, we drew a random sample of 30 obese sedentary workers divided into three groups of exercises: structured, spontaneous and mixed, each group consisting of 10 subjects. Inclusion criterion: 1) have agreed to participate in this study, 2) be obese sedentary male and female aged 18 years and over, 3 ) be present on the first and last day of the intervention and 4) to have consented in writing to participate in the study in accordance with the Helsinki Declarations. Exclusion criterion: Any obese sedentary worker who does not meet the inclusion criteria was excluded. 


\section{Description of Intervention Program}

The intervention program was randomized into 3 groups of physical exercises associated with the following nutrition education:

- group structured physical exercises + nutrition education low calorie, high in fiber and vitamins,

- group spontaneous physical exercises + nutrition education low calorie, high in fiber and vitamins and

- group of mixed physical exercises (structured physical exercises + spontaneous physical exercises + nutrition education low calorie, rich in fiber and vitamins).

\section{Structured Physical Exercises}

Structured, performed during physical activity such as jogging, rhythmic gymnastics, volleyball, basketball, swimming and cooking, and Abduction. A nutritional education break of 5 minutes after the activities during which the nutritional advice will be given again and / or given again (Adams et al., 1986):

\section{Volume}

1 hours a day, distributed as follows:

- 5 minutes warm up,

- 30 minutes of aerobic endurance exercise,
- 15 minutes of anaerobic endurance exercise (muscle building),

- 5 minutes of calm return and

- 5 minutes nutrition education break.

\section{Intensity}

Moderate to high progressive 50 to $80 \%$ of the spare heart rate, described by the following Heyward, 2010 and Karvonen, 2001 (Heyward, 2010) equation: Target $\mathrm{FC}=[(\%$ desired exercise intensity * (HR max - FC rest) + FC rest], \% FC $=$ FC of exercise 2 - FC rest 1 / HR max - FC1 whose maximum heart rate calculated by TANAKA formula, 2001 (HR $\max =207-0.7 x$ age) and the subjective perception of effort (Borg scale, 1998) for each of the activities practiced classified in Table 1.

\section{Frequency}

3 times a week of which:

- Tuesday: Aerobic endurance, anaerobic (reinforcement) and nutritional education breaks;

- Thursday: Aerobic endurance exercise and nutritional education break;

- Saturday: Aerobic endurance, anaerobic (reinforcement) and nutrition education breaks.

\begin{tabular}{|c|c|c|c|}
\hline & $\begin{array}{c}\mathrm{VO}_{2} \max (\%) \\
\text { Frequency Reserve heart }\end{array}$ & $\begin{array}{c}\text { \%Frequency of } \\
\text { Maximum heart rate }\end{array}$ & Scale of Borg \\
\hline Very light & $<25$ & $<30$ & $<9$ \\
\hline Slight & $25-44$ & $30-49$ & $9-10$ \\
\hline Moderate & $45-59$ & $50-69$ & $11-12$ \\
\hline Intense & $60-84$ & $70-89$ & $13-16$ \\
\hline Very intense & $\geq 58$ & $\geq 90$ & $>16$ \\
\hline Maximum & 100 & 100 & 20 \\
\hline
\end{tabular}


Practical steps

1. Warm-up (5 minutes, 3 times a week): The dynamic warm-up is done standing up, walking, trotting while performing joint movements of the neck, shoulders, arms, waist, knees and feet (raising and lowering, rotating, bending and extending) and stretching.

2. Physical exercises of aerobic endurance: 30 minutes, 3 times a week including:

a) 10-minute structured jogging exercises including: 30 seconds of running +1 minutes of brisk walking and 2 minutes of slow walking then $3 \times 2$ minutes of continuous running every 5 days continuously with 30 seconds of dynamic recovery,

b) Aerobic gymnastics 15 minutes, 3 times a week rhythmic dance;

3. Physical exercises of anaerobic endurance (Strengthening): 10 minutes, twice a week, 2 or 3 sets of 12 progressive repetitions. The exercises are performed in ideal starting position: standing, kneeling, elongated, four legs and sitting with lumbar support. The positions are adapted to each type of exercise, muscular group and degree of freedom. These are flexion-extension, abductionadduction, elevation, rotation, tilt, beat, bridge and scarab exercises performed with light free weights close to maximum progressive determined in function of the adaptability of the individual and the body link. We will systematically strengthen the muscles of:

a) Upper limbs and trunk (4 minutes): These are exercises performed with light free weights determined according to your physical form, a medium fast movement and fairly long repetitions with very short rest time between the series,

b) Lower limbs (4 minutes) performed with a heavy load, a slow movement, short recoveries and

c) Abdominal, dorsal and gluteal (2 minutes) with a load close to the maximum (plus or minus $70 \%$ of the max load), high intensity and fast movement and long enough series.
4. Sports activities in fun form of 5 minutes, 3 times a week and / or: Basketball, volleyball, swimming, football, nzago, and dance etc.

5. Relaxing Exercises (5 minutes): 3 minutes of dynamic stretching is done standing up, walking, trotting while performing spring movements of joints of the neck, shoulders, arms, height, knees and feet (raising and lowering, rotation, flexion and extension), a minute of static stretching consisting of holding the given position for 10 to 30 seconds and a minute of the movements of breathing which consists of inhaling slowly and long through the nose, the belly swells. Block the breath for a moment and slowly release the air through the mouth, the belly digs, repeat this cycle of inspiration and expiration 5 times. When doing exercises, exhale by contracting the muscles and inhaling when you release the contraction.

\section{Spontaneous Physical Exercises}

Every day, such as climbing stairs, getting up from a chair, sweeping, walking (Adams et al., 1986), etc. These physical exercises of daily living and specialized physical activities (organized or unorganized, supervised or not) are part of a physically active lifestyle while active lifestyle exercise is the way of being and the ways to live individually or in groups that integrate the practice of various physical activities, of varying frequency, duration and intensity, for the benefits related to them. Thus, they are mixed asynchronous when they combine the type of endurance and reinforcement that are executed one after another in a session, but are not performed simultaneously in the same fraction of volume while they are synchronous when they are carried out simultaneously in the same fraction of volume.

They are composed of:

1. The fast walk of 10000 not recorded using a pedometer and leisure sports activities of choice recorded on an activity journal on the odd day either at home or after the service on a weekly basis (Monday, Wednesday and Friday), Saturday and Sunday afternoons.

2. Lifestyle exercise at work and / or at home: 
a) In the office to sit, the seat should not be too low or too high. Too low, the knees go up to the chin, the lumbar spine rounds and gets tired. The thighs should form an almost straight angle with the bust, feet resting on the ground. Above all do not slouch, stow your back well at the bottom of the seat and avoid crossing your legs. The entire spine rests on the shoulders and buttocks;

b) Sit up regularly in his seat by mobilizing the cervical area, and making deep inspirations / regular expirations;

c) Do not sit in your chair wherever you are more than two hours of the time;

d) Put your phone and printer on a remote corner of your table on your desk so you can move when needed;

e) Go up the stairs several times a week instead of the elevator every day;

f) Deposit your signatory on the other table away from yours;

g) During breaks or if you want to go to the toilet, go to the one located further or another floor;

h) Get up and fetch water from the tap or kitchen of another service;

i) Practice at least 10 minutes of break time in your office;

j) Keep your car 20 or 30 meters from the workplace or go for a walk

k) Book a meeting on foot with colleagues ...

\section{Nutrition Education}

These physical exercise programs have been associated with nutrition education based on low calorie dietary advice, high in fiber, protein and vitamins, every working day including Monday, Tuesday Wednesday, Thursday and Friday respectively on the:

- time of taking meals (lunch, dinner and supper);

- quantity of meals (light and heavy);
- quality of meals (nutritional and / or balanced constituents in proportion to: protein, lipid and carbohydrate);

- diversification of meals (method of preparation, fiber, protein and vitamins) and

- Adaptation of meals (types and half green lemon juice mixed with a teaspoon of natural honey and quail eggs).

Nutritional education low calorie, high in fiber and vitamins prescribed: The low-calorie, fiber-rich, and prescribed nutrition education consisted of advising participants to consume cabbage soup morning, noon, and night for a week. The ingredients of this famous soup are: cabbage, tomato, carrot, celery, onion, garlic and parsley.

This soup is improved every day by adding two or three additional seasonal vegetables, boiled together, without fat and absorbed as is and limiting the drinks to water and tea. This formula is repeated after an interval of 1 to 2 weeks per month.

A typical week of the cabbage soup diet was as follows:

- On the first day there is a cabbage soup with all-you-can-eat fruit except bananas, watermelons and strawberries;

- The second day is cabbage soup with an allyou-can-eat vegetable accompaniment with the exception of legumes such as peas, corn and beans;

- The next day, it is still the cabbage soup with fruits and vegetables at will, the exceptions mentioned for the first two days are valid for this day too;

- On the fourth day, the soup is accompanied by bananas and skimmed milk up to 1 liter in the day;

- On day 5, it is accompanied by beef cooked without fat and unseasoned tomatoes.

- On day 6, 150 grams of veal, beef or chicken without skin is added to the soup with green vegetables at will and 
- The last day is composed of soup with whole rice, green vegetables at will and unsweetened fruit juice.

Admittedly, this diet has been associated with a mixture of half a glass of lemon juice with two quail eggs (once a day in the morning). It allows you to lose weight fast enough, limiting the feeling of hunger thanks to the large amount of fiber contained in the vegetables consumed, while bringing a feeling of well-being related to the cleansing of the body. However: 1) The quail egg is balanced because it is very rich in protein. It can cause an increase of the mass and the muscular force quite important as well as essential fatty acids, in proteins, in fat-soluble vitamins, in iron and in calcium, 2) Lemon is a powerful antiseptic, so eliminate toxins and germs from the body, putting the body in ideal conditions to lose weight. It would also cleanse the liver, which is a central organ in the process of digestion. In addition to the large amount of vitamin $C$ to fight against asthenia and increase secretions of gastric juice and saliva with citric acid.

\section{Data Gathering}

The anthropometric parameters collected were as follows: 1) weight (kg) measured using a SECA brand scale calibrated in kilograms $(\mathrm{kg})$ to 100 grams and an indemeter scale, 2) size $(\mathrm{cm})$ with the help of a mark SECA, 3) waist circumference $(\mathrm{cm})$ was measured using a new tape measure, 4) the body mass index (BMI) of workers was calculated using the following formula: BMI: mass $(\mathrm{kg}) /$ height (m). According to the World Health Organization (WHO) and obesity was determined by a BMI value greater than equal to $30 \mathrm{~kg} / \mathrm{m}^{2}$.

\section{Statistical Analyzes}

Quantitative variables were expressed as mean \pm standard deviation. The ANOVA test was used to compare the variables of two groups. A value of $p-$ value $\leq 0.05$ was considered a threshold of statistical significance.

\section{Results}

Table 2 compares the effects of different types of exercise routines on the morphological variables of obese workers of the Multimodal Freight Management Office.

A reduction in weight, waist circumference, and body mass index was observed in the intra group before and after the exercise programs. After the intervention, the group Mixed exercises improved more significantly $(p=0.0001)$ the morphological parameters of obese than the group structured exercises and spontaneous exercises associated with a nutritional education.

\section{Discussion}

The present test study showed that, the mixed exercise diet program significantly improves morphological parameters more than the structured and spontaneous physical exercise with diet after three months of intervention programs, $p$ $=0.001$. To this end, an American study has shown that lifestyle changes are more beneficial than nonpharmacological treatments and the prevalence of risk factors for obesity in general and in particular cardiovascular risk related to metabolic syndrome (Stefanick et al., 1998; Knowler et al., 2002; Bauman et al., 2004).

The STRRIDE study of men and women aged 40 to 65 followed for 8 months showed that moderate or high intensity exercise significantly reduced morphological parameters (Slentz et al., 2004).

In fact, for people who want to lose weight, the most obvious defect of the strategy relying only on the low-calorie diet is that, in $95 \%$ of cases, it does not give the expected results (Kraner et al., 1989; Stunkard et al., 1959). Research has repeatedly shown that weight loss programs that focus on both increased physical activity and reduced dietary energy intake help to reduce weight in the short and long term. only those based on diet (Miller et al., 1997; Ross et al., 2000; Wing et al., 1999). 
Table 2

Comparisons of morphological variables by type of structured, spontaneous, and mixed physical exercise in the intra group before and after intervention according to the different types of exercise programs.

Before the intervention program

\begin{tabular}{|c|c|c|c|c|}
\hline & Structured exercises & Spontaneous exercises & Mixed exercises & \\
\hline & Before & Before & Before & \\
\hline Weight (kg) & $91 \pm 9.5$ & $90 \pm 9.5$ & $92 \pm 9.5$ & 0.741 \\
\hline Waist circumference $(\mathrm{cm})$ & $110 \pm 10$ & $109 \pm 10$ & $111 \pm 10$ & 0.381 \\
\hline BMI $\left(\mathrm{kg} / \mathrm{m}^{2}\right)$ & $32.5 \pm 13.4$ & $32.1 \pm 13.4$ & $32.8 \pm 13.4$ & 0.985 \\
\hline
\end{tabular}

After the intervention program

\begin{tabular}{lcccc}
\hline & \multicolumn{2}{c}{ Structured exercises } & Spontaneous exercises & Mixed exercises \\
\cline { 2 - 3 } & After & After & After & \\
\hline Weight $(\mathrm{kg})$ & $83 \pm 8.9$ & $85 \pm 8$ & $75 \pm 7.21$ & 0.0001 \\
Waist circumference $(\mathrm{cm})$ & $104 \pm 9.8$ & $107 \pm 8.1$ & $100 \pm 8.5$ & 0.0001 \\
BMI $\left(\mathrm{kg} / \mathrm{m}^{2}\right)$ & $29.6 \pm 14.1$ & $30.3 \pm 12.4$ & $26.7 \pm 11$ & 0.0001
\end{tabular}

According to the Guide Clinical Guidelines on Obesity, published by the US National Institutes of Health, the most effective approach to reducing and stabilizing weight includes both a decrease in daily caloric intake, an increase in physical activity. There is also a record of people who manage to maintain weight after weight loss. In 2000, 760 women and 170 men had managed to maintain an average loss of $27 \mathrm{~kg}$ after 6 years by controlling their fat intake and regular vigorous physical activity (McGuire et al., 1999a, McGuire et al., 1999b).

Jeffery has shown that the higher the energy expenditure associated with physical activity, the greater the weight loss (Jeffery et al., 2003). Thus, the regular practice of a sufficient volume of physical activity can play a decisive role, because it allows obese people not to regain the weight lost after a slimming program. In a study by Conway and his associates, which included a low-calorie diet and a spontaneous exercise program, obese people improved their weight, waist circumference, and Body Mass Index. Ross and his collaborators have achieved much the same results, a reduction in weight of about $11 \mathrm{~kg}$ (Ross et al., 2000; Conway et al., 1995).

However, the results currently available support the hypothesis that a combination exercise program with low-calorie diet, rich in fiber and vitamins, would improve the health status of obese sedentariness more than those achieved by dieting alone and / or with a structured and spontaneous exercise program.

\section{Conclusion}

A moderate-to-high-intensity, high-volume, lowcalorie diet, rich in fiber and vitamins exercise program significantly improves the morphology of sedentary obese workers than the structured and spontaneous exercise program. It can be considered as an effective non-pharmacological strategy to combat the nutritional and epidemiological transition in the workplace, where obesity is the main cornerstone. 


\section{References}

Adams SO, Grady KE, Wolk CH, Mukaida C. Weight loss: a comparison of group and individual interventions. J Am Diet Assoc, 1986; 86: 485-490.

Alberti KG, Zimmet P, Shaw J. The metabolic syndrome--a new worldwide definition. Lancet, 2005; 366: 1059-1062.

Alexander CM, Landsman PB, Teutsch SM, Haffner SM. NCEP-defined metabolic syndrome, diabetes, and prevalence of coronary heart disease among NHANES III participants age 50 years and older. Diabetes, 2003; 52: 1210-1214.

Bauman A, Miller Y. The public health potential of health enhancing physical activity. In: oja P, Borns J., eds. Healthenhancing physical activity. International Council of Sport Science and Physical Education, 2004.

Borg G. Borg's Perceived Exertion and Pain Scales: Human Kinetics; 1. Edition, 1998: pp. 369.

Bucher HC, Hengstter P, Schindler C, Guyatt GH. Percutanous transluminal coronary angioplasty versus medical treatment for non-acute coronary heart disease metaanalysis of randomised controlled trials. BMJ, 2000; 321: 7377.

Chakravarthy MV, Joyner MJ, Booth FW. An obligation for primary care physicians to prescribe physical activity to sedentary patients to reduce the risk of chronic health conditions. Mayo Clin Proc, 2002; 77(2): 165-173.

Conway JM, Yanovski SZ, Avila NA, Hubbard VS. Visceral adipose tissue differences in black and white women. Am J Clin Nutr, 1995; 61: 765-71.

Dekker JM. Girman C, Rhodes T, Nijpels G, Stehouwer CD, Bouter LM, Heine RJ. Metabolic syndrome and 10-year cardiovascular disease risk in the Hoorn Study. Circulation, 2005; 112: 666-673.

Dietz WH. The role of lifestyle in health: the epidemiology and consequences of inactivity. Proc Nutr Soc, 1996; 55: 829840 .

Fung TT, Willett WC, Stampfer MJ, Manson JE, Hu FB. Dietary patterns and the risk of coronary heart disease in women. Arch Intern Med, 2001; 16(1): 1857-62.

Grundy SM, Cleeman JI, Daniels SR, Donato KA, Eckel RH, Franklin BA, Gordon DJ, Krauss RM, Savage PJ, Smith SC Jr, Spertus JA, Costa F. Diagnosis and management of the metabolic syndrome: an American Heart Association/National Heart, Lung, and Blood Institute Scientific Statement. Circulation, 2005; 112: 2735-2752.

Han TS, Seidell JC, Currall JE, Morrison CE, Deurenberg P, Lean ME. The influence of height and age on wait circumferences as on index d'adiposity in adults. International Journal of Obesity and Related Metabolic Disorders, 1997; 21: 83-89.

Heyward V. Advanced fitness assessment and exercise prescription (Six th Edition ed.). US: Human Kjnetics, 2010.

Hippocrates. On the articulations. The genuine works of Hippocrates. Clin Orthop Relat Res, 2002; (400): 19-25.

Jeffery RW, Wing RR, Sherwood NE, Tate DF. Physical activity and weight loss: does prescribing higher physical activity goals improve outcome? Am J Clin Nutr, 2003; 78: 684-9.

Knowler WC, Barrett-Connor E, Fowler SE, Hamman RF, Lachin JM, Walker EA, Nathan DM. Reduction in the incidence of type 2 diabetes with lifestyle intervention or metformin. N Engl J Med, 2002; 346: 393-403.

Kramer FM, Jeffery RW, Forster JL, Snell MK. Long-term follow-up of behavioral treatment for obesity: patterns of weight regain among men and women. Int J Obes, 1989; 13: 123-36.

McGuire MT, Wing RR, Klem ML, Lang W, Hill JO. What predicts weight regain in a group of successful weight losers? J Consult Clin Psychol, 1999b; 67: 177-85.

McGuire MT et al. Behavioral strategies of individuals who have maintained long-term weight losses. Obes Res 1999a; 7:334-41.

Miller WC, Koceja DM, Hamilton EJ. A meta - analysis of the past 25 years of weight loss research using diet, exercise or diet plus exercise intervention. Int J Obes Relat Metab Disord 1997; 21:941-7.

National Institutes of Health Clinical guidelines on the identification, evaluation, and treatment of overweight and obesity in adults: the evidence report. National Institutes of Health NIH Publication 1998; 98-9043.

Pedersen BK, Saltin B. Evidence for prescribing exercise as therapy in chronic disease. Scandinavian journal of medicine and science in sports, 2006; 16 (1): 3-63.

Poon PP, Zuck N, Plotnikoff R., Horne T. Work place Active Living in Alberta: A Needs Assessment. Edmonton: Alberta Community Development, 2000.

Roberts CK, Barnard RJ. Effects of exercise and diet on chronic disease. Journal of Applied physiology, 2009; 93(3): 3-30.

Ross $\mathrm{R}$ et al. Reduction in obesity and related comorbid conditions after diet-induced weight loss or exerciseinduced weight loss in men: a randomized, controlled trial. Ann Intern Med 2000; 133:92-103.

Ross R, Janssen I. Physical activity, total and regional obesity: dose-response considerations. Med SCI Sports Exerc, 2001, 33(6): S521-S527.

Scherr J, Wolfarth B, Christle JW, Pressler A, Wagenpfeil S and Halle M. Associations between Borg's rating of perceived exertion and physiological measures of exercise intensity. European Journal of Applied Physiology, 2013; 113: 147155. 370.

Slentz CA, Duscha BD, Johnson JL, Ketchum K, Aiken LB, Samsa GP, Houmard JA, Bales CW, Kraus WE. Effects of the amount of exercise on body weight, body composition, and measures of central obesity: STRRIDE-a randomized 
controlled study. Arch Intern Med, 2004; 164: 31-39.

Stefanick ML, Mackey S, Sheehan M, Ellsworth N, Haskell WL, Wood PD. Effects of diet and exercise in men and postmenopausal women with low levels of HDL cholesterol and high levels of LDL cholesterol. N Engl J Med, 1998; 339(1): 12-20.

Stunkard A, Mc Laren-Hume M. The results of treatment for obesity: a review of the literature and report of a series. AMA Arch Intern Med, 1959; 103: 79-85.
Van GL. Obésité: Physiopathologie risques et traitement. Endocrinologie IX 1/Nutrition 1991: 1 :18-32.

Verori I. Inactivity as a disease risk and health benefits of increased physical activity. In: Oja P, Borms J, eds. Healthinhancing physical activity. International council of sport science and physical Education, 2004.

Wing RR. Physical activity in the treatment of the adulthood overweight and obesity: current evidence and research issues. Med Sci Sports Exerc 1999; 31: S547-52. 